\title{
MODERNE INDIASE KUINST IN HET RIJKSMUSEUM: SUBODH GUPTA
}

Toen het Aziatisch Paviljoen in april 2013 na het grondig verbouwen van het Rijksmuseum Amsterdam feestelijk werd geopend, bestond de daar tentoongestelde collectie Indiase kunst vooral uit antieke bronzen en stenen sculpturen daterend tussen 200 en 1600. Dit had te maken met het verzamelbeleid dat tot 2013 gold. India is echter een moderne natie die een belangrijke rol speelt in de wereldpolitiek en -economie. Bij dit imago hoort ook moderne kunst. Hoewel Indiase hindoe, jaina en boeddhistische cultusbeelden, en de pracht en praal van wapens, glas en sieraden, hoog worden gewaardeerd door de meeste museumbezoekers, is moderne kunst uit het subcontinent onbekend terrein. Daarom werd besloten om, voorlopig gedurende een jaar, in het Paviljoen ook moderne Indiase kunst te tonen. De ereplaats als eerste vertegenwoordiger van moderne Indiase kunst viel toe aan Subodh Gupta, een van de populairste Indiase kunstenaars, wiens oeuvre wordt vergeleken met dat van Damien Hirst, Jeff Koons en Ai Weiwei, en wiens sculpturen miljoenen opbrengen op de internationale kunstmarkt.

Subodh Gupta begon zijn adembenemende carrière met schilderen. Daarna kwamen sculpturen, en in 2011 was hij zelfs te zien - zichzelf spelend - in de Bollywood-productie Ra.One, een 'science-fiction superhero film'. Deze Bollywood-episode, die sommige van zijn bewonderaars oprecht shockeerde, valt wellicht beter te begrijpen als we kijken naar Subodh Gupta's biografie, die zelf ook veel weg heeft van een filmscenario. Gupta werd in 1964 geboren op het platteland van Bihar, een regio die in nieuwsberichten vooral bekend staat om armoede en geweld. Zijn dorp Khagaul, een belangrijk spoorwegknooppunt waar iedereen, inclusief Gupta's vader, bij de spoorwegen werkte, leek, in de woorden van Gupta zelf, op een 'Wild West frontier town ${ }^{1}$ ': bijna iedere dag werd er iemand vermoord. De enige kunst in het dorp bestond uit de godenbeelden in de lokale tempel, en de voorstellingen door rondreizende theatergezelschappen. Van moderne en abstracte kunst had niemand ooit gehoord. Toch voelde Gupta altijd dat dit zijn weg was: "I have always felt I'm an artist, even from the very beginning when I started to draw and paint but didn't know what art really meant", vertelt hij in een van zijn interviews. Na het behalen van zijn BA aan the College of Art in Patna, waar hij zich vooral richtte op schilderen, verhuisde Gupta naar New Delhi. Naast Mumbai en Calcutta is dit een van de weinige plaatsen in India waar een moderne kunstenaar zich kan ontplooien.

In New Delhi begon hij te experimenteren met andere vormen van expressie: sculptuur, video en performance. Na een aantal magere jaren kreeg hij uiteindelijk succes met tentoonstellingen overal ter wereld, van Mumbai en Zuid-Korea tot Parijs, New York en nu ook Amsterdam. 


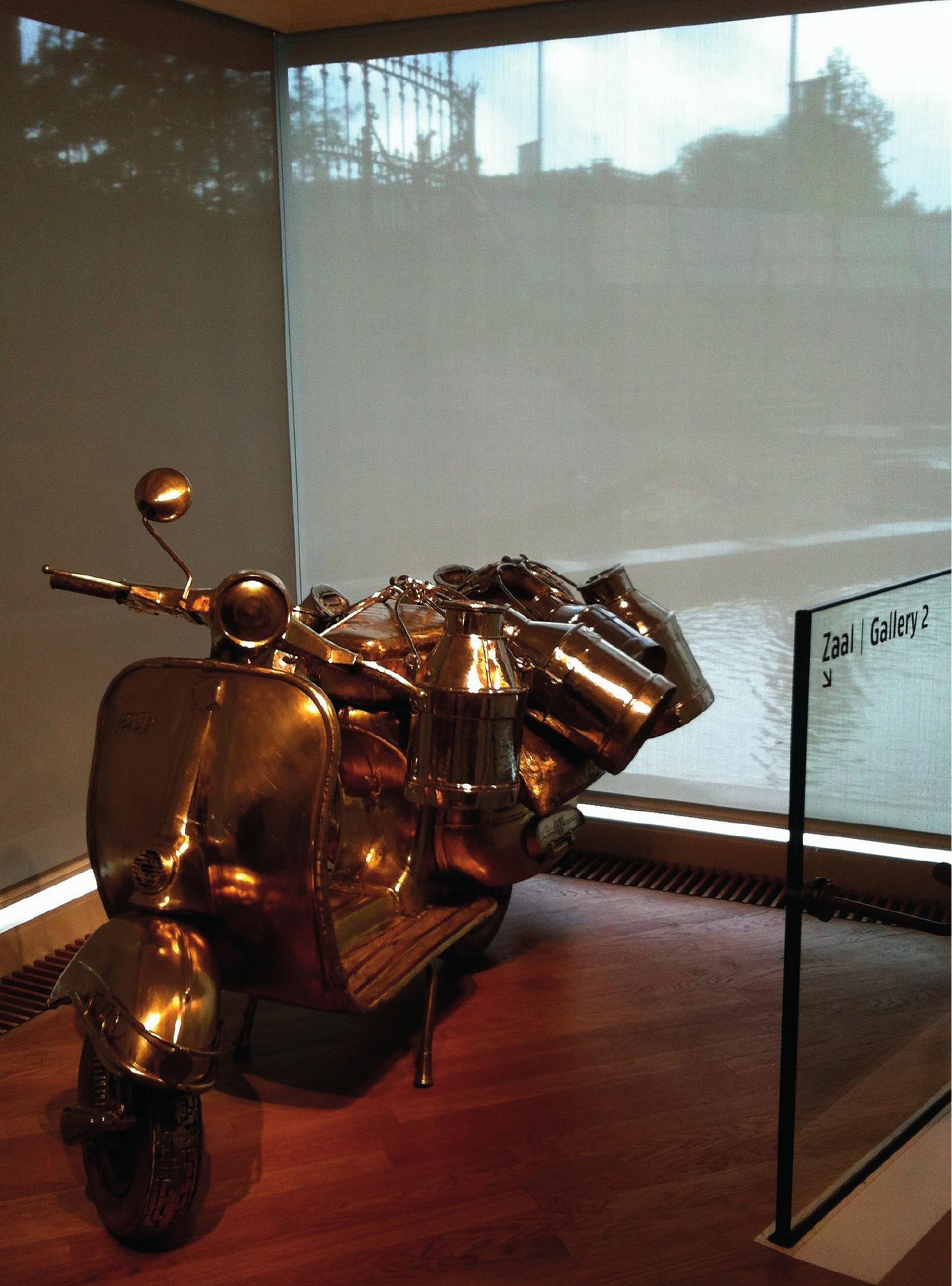


Afb. 1 (links)

Subodh Gupta

(1964-), This Side is

the Other Side (edition

1/3), nikkelbrons,

70 x 105 x 70cm.,

India, Rijksmuseum

Amsterdam, inv.nr.

AK-C-2014-1.

Afb. 2

Subodh Gupta's werk voor de ingang van

Christie's New York

tijdens Asia Week 2014.

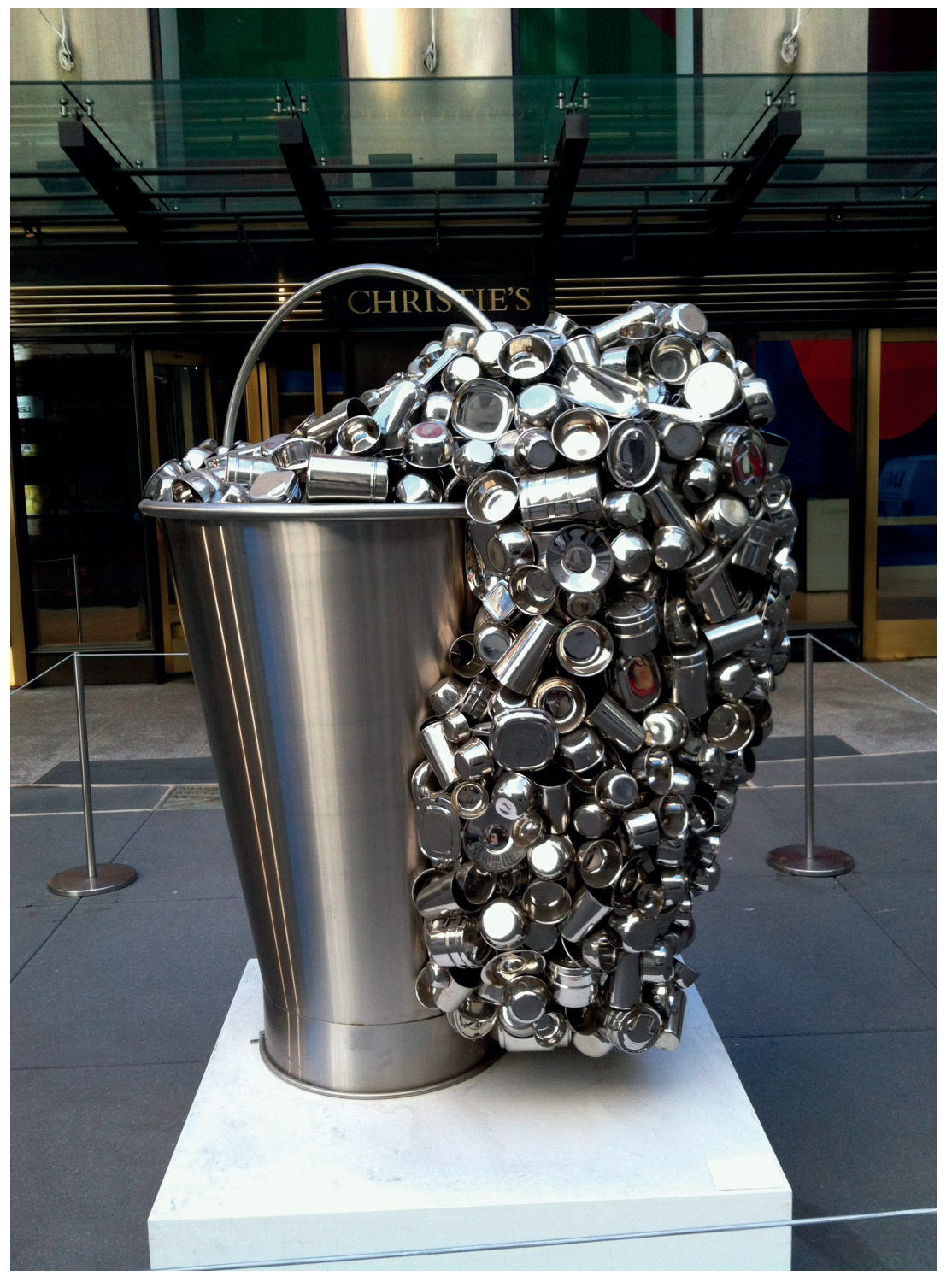

Gupta's This Side is the Other Side (afb. 1) is sinds 3 oktober 2014 te zien in het Rijksmuseum Amsterdam en zal één jaar worden getoond. Het beeld staat boven aan de trappengang die leidt naar de benedenverdieping van het Aziatisch Paviljoen. De moderne vorm past goed bij de asymmetrische witte muren en glazen wanden van het Paviljoen. Het warme gouden glas van de bronzen scooter weerspiegelt in het water dat het Paviljoen omringt.

Subodh Gupta haalt zijn inspiratie vooral uit het dagelijks leven, uit objecten die onderdeel zijn van een populair beeld van India. Roestvrij stalen potten, pannen en melkbussen, en duidelijk herkenbare vervoermiddelen: Bajajscooters en Ambassador-taxi's werden zijn handelsmerk. Zijn onmiskenbaar Indiase maar niet door clichés geteisterde stijl valt in de smaak bij veel verzamelaars. Voor de expats, maar ook voor Indiërs uit grote steden, zijn

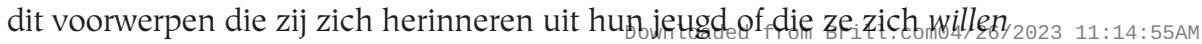


herinneren. Gupta wil echter niet als een regionale of 'Indiase' kunstenaar worden gezien. Hij benadrukt dat, alhoewel de objecten die hij in zijn installaties gebruikt essentieel Indiaas zijn, de thema's die hij probeert over te brengen universeel zijn. Zoals het contrast tussen de glitterende buitenkant van het roestvrij stalen keukengerei en de leegte erbinnen. Hij merkt op: "The poor, the middle class and the rich use [these objects] at home. In this country, how many people have the utensils but they starve because there is no food?"

This Side is the Other Side lijkt een verdere variatie op hetzelfde thema, maar met een speciale draai. De scooter, met melkbussen die aan beide kanten hangen, is een gemechaniseerde koe, een 'stadskoe'. Hij symboliseert het snel moderniserende platteland. En het gepolijste, goud-glimmende oppervlak past bij een object van verering, een rol die - in verschillende culturele contexten - zowel door een koe als door een kunstwerk kan worden vervuld. Maar is dat niet slechts een blinkend omhulsel?

- Dr. Anna Slaczka is conservator Indiase kunst bij het Rijksmuseum Amsterdam. Zij promoveerde (2006) in Leiden op het gebied van Sanskriet en Indiase kunst. Ze richt zich op contacten tussen Zuid- en Zuidoost-Azië, iconografische Sanskrietteksten, kunst en architectuur van India en hindoetempelrituelen.

\section{Noten}

* Fotografie: Anna Slaczka

1. 'Subodh Gupta: cow dung, curry pots and a hungry god', by Pernilla Holmes, ARTnews, 09/01/2007. (www.artnews.com/2007/09/01)

2. http://www.tompietrasik.com/2009/10/16/subodh-gupta-and-indian-contemporaryart/ 